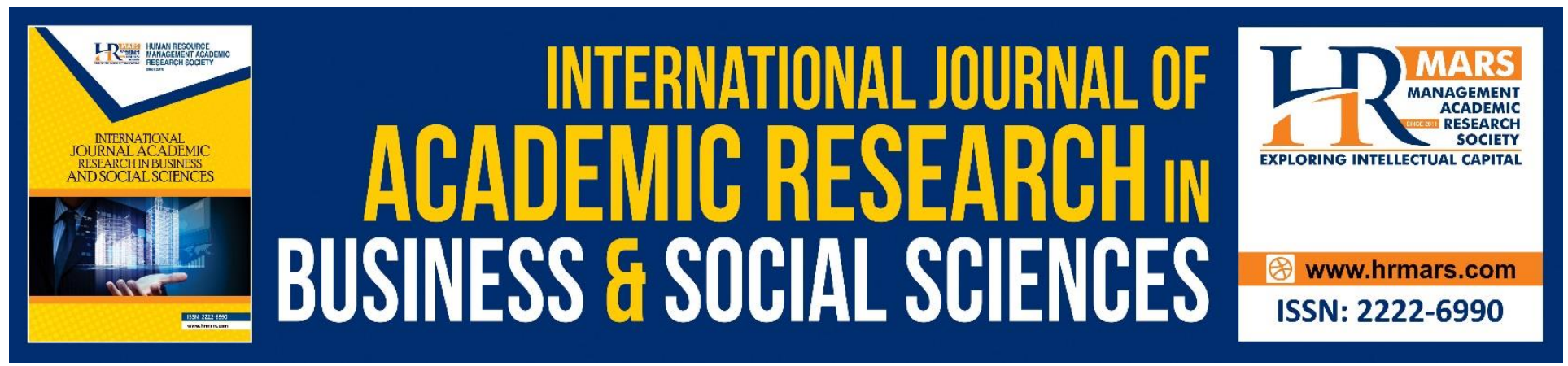

\title{
Blog: A Platform towards Democratization of Information in Malaysia
}

\section{Muhammad Hakimi Tew Abdullah, Hoo Fang Jing, Abdul Rauf Ridzuan, Wan Hartini Wan Zainodin}

To Link this Article: http://dx.doi.org/10.6007/IJARBSS/v9-i3/5731

DOI: $\quad 10.6007 /$ IJARBSS/v9-i3/5731

Received: 07 Feb 2019, Revised: 19 Feb 2019, Accepted: 22 March 2019

Published Online: 29 March 2019

In-Text Citation: (Abdullah, Jing, Ridzuan, \& Zainodin, 2019)

To Cite this Article: Abdullah, M. H. T., Jing, H. F., Ridzuan, A. R., \& Zainodin, W. H. W. (2019). Blog: A Platform towards Democratization of Information in Malaysia. International Journal of Academic Research in Business and Social Sciences, 9(3), 626-640.

\section{Copyright: (C) 2019 The Author(s)}

Published by Human Resource Management Academic Research Society (www.hrmars.com)

This article is published under the Creative Commons Attribution (CC BY 4.0) license. Anyone may reproduce, distribute, translate and create derivative works of this article (for both commercial and non-commercial purposes), subject to full attribution to the original publication and authors. The full terms of this license may be seen

at: http://creativecommons.org/licences/by/4.0/legalcode

Vol. 9, No. 3, 2019, Pg. 626 - 640

http://hrmars.com/index.php/pages/detail/IJARBSS

JOURNAL HOMEPAGE

Full Terms \& Conditions of access and use can be found at http://hrmars.com/index.php/pages/detail/publication-ethics 


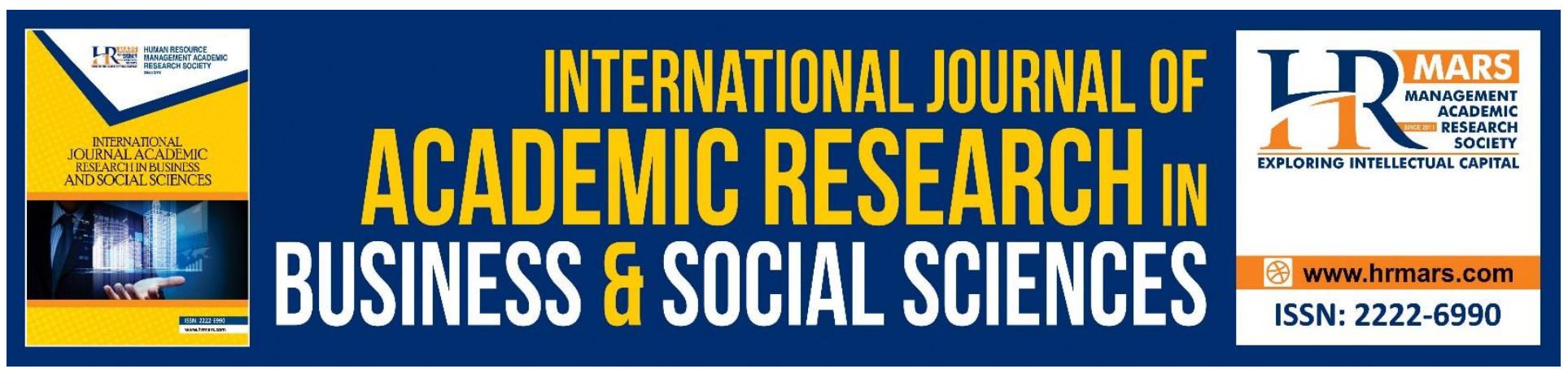

\title{
Blog: A Platform towards Democratization of Information in Malaysia
}

\author{
Muhammad Hakimi Tew Abdullah, Hoo Fang Jing, Abdul Rauf \\ Ridzuan, Wan Hartini Wan Zainodin \\ Universiti Teknologi MARA (UiTM), Negeri Sembilan Branch Campus, Malaysia
}

\begin{abstract}
The vast development in information technology nowadays has brought a shift to change politics in Malaysia. Blogs have then become an influential medium in reporting various news as our community begins to reject mainstream media due to the fact that this reported news were bias. In countries that do not practice freedom of media, blogs will serve as an important medium in the dissemination of information to the public which was often deemed as lacking of new information and was not presented by the mainstream media. Thus, this research paper is looking into how blogs have unfolded a pathway towards the democratization of information in Malaysia. This study has used a qualitative approach by conducting in-depth interviews on two blogger groups comprising of different political ideologies. A total of eight well-known bloggers in Malaysia were selected as participants. The results show that blogs have opened a new platform in delivering information to the community. Besides that, laws or acts that can be imposed to bloggers do not stop the bloggers from expressing their opinions freely. Additionally, an exposure to the identity of a blogger has led to an increase in the credibility of a blog. Blogs are also seen to have a strong influence on the public's mind. Exposing to disclose news or events by bloggers is seen as an effort to provide important information for the public to view the truth from the disseminated information. It also turns out that freedom of speech through cyberspace especially blogs has taken place in Malaysia. However, the stated freedom is not absolute.
\end{abstract}

Keywords: Blog, Credibility, Democracy, Freedom Of Speech, Politics.

\section{Blogosphere: Introduction to blog networks}

The role of political blogs in the public network is hard to deny especially before and after the election. The emergence of new media has led to the occurrence of the phenomenon of blogs that has great influence in today's society and it is through establishing a new space called the blogosphere. The term was used in describing the blogosphere and defining the phenomenon of political blogs in cyberspace. Roth (2004) stated that online political blogs were used to express 
opinion and deliver information where pieces of the information were acquired and linked in new ways that represent the mainstream media.

The blogosphere occurs when the existing use of media is difficult to be accessed by certain groups to disseminate information to its readers. Information and issues highlighted and debated in blogs are seen more independent. Democracy through the internet has opened a new dimension in the process of communication and dissemination of information. According to Akmal and Salman, (2015) new media was used as a medium that facilitates selected information to be disseminated in which the information can be accessed without restriction and users are free to share and be heard through expressed opinions democratically. Abdullah et. Al, (2016) in turn noted that blog has attracted the interest of Malaysians in 1998 which at that time bloggers were enthusiastically writing and posting concerned politics and current issues.

Blogs have also become an influential medium in reporting news whenever the community rejects the mainstream media that has always be seen often as favoring the Government. Inch, (2015) affirms that political participation needs people to establish a democratic political participation. With this, it will somehow influence the decision makers as readers were deprived of certain information as well as they will always want more news due to the fact that the mainstream media is often controlled by the government.

\section{Background Study}

Since Malaysian government practiced the freedom of press in the mid-1990s and with no online screening with the use of internet in the Communications and Multimedia Act 1998, blogs have brought a lot of new changes in the dissemination of information over the internet (Baharuddin et al, 2008). Trends in the use of new media, especially blogs have been seen as an alternative for some options in delivering their political information. Koop (2006) stated that blogs have been widely used in various purposes including news sources, entertainment, and new sources of information, political campaigning medium, and business fields. Among today's popular blogs is political blogs as it has created a space that is free for political debate. We could see also that, blogs and politics cannot be separated where the use of blogs in Malaysia is often associated with politics lately.

The emergence of blogs has opened up a new platform for media users to express their opinions freely in cyberspace. Blogs have been used as one of the alternative sources among the people when the mainstream media are seen frequently monopolized by the government. The use of blogs is intense after the $11^{\text {th }}$ General Election. It has been widely used during the $12^{\text {th }}$ General Election where remarkable results were shown and has shocked users who were directly or indirectly involved in politics.

The influence of blogs was seen clearly again in the 13 th General Election (GE) on the $5^{\text {th }}$ Mei 2013. The results were unexpected whereby more users were braver to express their opinions and hopes regarding the democratic system in Malaysia. Malaysians were called to change the party that has long reigned in Malaysia since independence. Most of the blogs were in favour of the opposition expressed their intention by shouting Ubah and Ini Kalilah. The effect of this has led to a new dynamic in the competition among different political parties in Malaysia that has fought for various ideologies and walks towards the glory of winning with the parties they represent. 
An unexpected result has stunned all parties, especially for the Barisan Nasional in the 14th General Election to see a large number of new and old voters came to vote in almost all areas in Malaysia, causing Pakatan Harapan to conquer Putrajaya. This phenomenon has shocked the whole world where the combined power of voters with various information through new media such as blogs, Facebook, twitter, Instagram and so on led to a major change in Malaysia's leadership today after the well-known blogger chedet.com owned and managed by Tun Dr Mahathir Mohamad himself was chosen to lead the country for the second time as the Prime Minister in the history of Malaysia's leadership. Thus, this phenomenon has then created a strong desire for researchers to exploit the question on how far- fetched can an identity of a blogger influence the credibility of a blog? Is freedom of speech through cyberspace (blog) a great impact in changing the landscape of information in Malaysia?

\section{Research Methodology}

This study was conducted using a phenomenology approach through qualitative method in an in-depth interview on eight selected bloggers. They were placed under two groups of different political ideologies. Categorization is based on the blogger's background information as well as the tendency of political stance shown by bloggers in the blog post. The eight bloggers chosen are the most influential people in the blogging world in Malaysia. This study has used a deductive approach in formulating data collection methods as a result of the conducted interviews. Then the data was analyzed manually through 'thematic analysis.'

\section{Results and discussions}

\section{i.) Blogger is influential?}

In the Malaysia context, blogs are a medium that is not fully regulated or governed by the government. For Malaysia, which does not have the freedom of media, blogs have been used as a platform for people to find out the truth. Usually, a rationale blogger who comes up with rational and justifiable arguments, supported by strong facts, will surely succeed in influencing the minds of people who are always looking for something new and exciting.

How strong the influence of a blog is depends on who the blogger is, who is the blogger or who is the moderator of the blog. If the blogger is famous and has a high credibility, then surely he has a strong influence among his followers. A convincing writing style supported by the bloggers' quickwitted minds in coming out with a storyline indoctrinate with facts and clear evidences, and logical narrative will enable one to be influenced by his writing.

Today's blog turned out to be more influential than newspapers because to the younger generation nowadays, most of them have smartphones. Through the use of smartphones, they can surf blogs anytime and at any place only through links that have been made on face book as it is rarely seen for today's generation to carry newspapers with them. However, it still relies on the integrity and identity of a particular blogger. Blogger 7 states that;

"The identity and integrity that a blogger brings will accelerate and reinforce the people's trust in the issues he writes. For example, when choosing the correct party for leadership, some bloggers can write about the candidates by giving an overview of them and so on. It will somehow influence the election. This shows that the bloggers has their influence. " 
But, this study emphasises that the intended influence is much dependent on bloggers who have their own identity, credibility and integrity. The real incident to see the influence of real bloggers were during the fall of former Prime Minister Tun Abdullah Ahmad Badawi where bloggers had attacked him and there were no help received by Tun Abdullah Ahmad Badawi as he had rejected the new media, especially blogs at that time and for banning his ministers to have their own blogs and even practiced anti-blog. The Government under his leadership at the time was also not friendly to blog even they even practiced anti blog. What happened today also includes bloggers' ways in controlling the situation.

Blogger 2 explained that;

"A move to bring Najib down today is to use blogs like Mahathir blogs, Syed Akhbar blogs, Apanama blogs and so on where this blogger sets up an agenda. Now, Mahathir and his blogger faced more challenges and it was not as easy as during Pak Lah's time because Najib had his own blog to create dispute to what has been posted in the Chedet blog. So, it is a battle between blogs for both parties.

What is happening today involves the battle of blogs that are taking place between the groups under Mahathir with the group under Najib Razak. The mainstream media is still in control and has great influence on this blog, even though foreign newspapers report events or news taken from this revenue. Certainly due to the strong and powerful influence of Chedet.com blog, people are willing to wait for what will next be exposed by Mahathir. This clearly shows that the blog is influential.

Blogger 3 also supports the statement made by Blogger 2 through its description that;

"The blog is not possible by itself but if it is joined in a community and battle for the same beliefs, it will then be a strong influence. But if individuals try to influence the society it may be difficult. But, like Tun Mahathir, he has more dynamism than all bloggers. So he has his own strength as one who has changed history. "

Additionally, bloggers can also be regarded as an influential blogger when they receive a high number of hits as a sign of high number of readers in a given period. One of the examples that can be given besides Tun Mahathir is Din Merican another blogger throughout the year 2014 who has recorded a total of hits of 2.5 million visits from 206 countries around the world according to the annual report released by WordPress.

According to Blogger 8 ,

"Blog has provided a wide variety of information to the community in the world in relation to Malaysia. I would like to share my own ideas and experience, showing what is being done by the community around the world, in respect of democracy, of good governance, about the problem of corruption and all kinds of issues with respect to the country." The influence gained by blogger 8 was not used to bring down the country. In addition, he said that "criticizing and to bring down the country are two different things. "So bloggers in Malaysia that holds Malaysian citizenship are advised to keep the good name of the country as no one can change one's identity as a Malaysian citizen. Therefore, proper and ethical ways must be taken into serious consideration to keep the well- being and harmony among Malaysians together. 


\section{ii.) Provide important information to the readers}

Good articles are articles that provide education to readers. Materials and information should come from reliable sources with high levels of credibility. This will then encourage people to read. Blog is actually educational materials that consist of political issues, social issues, issues regarding human rights and so on where the emphasis is to educate, share and communicate. It should be noted that education will only occur if certain bloggers display true and reliable information based on facts and not just condemn or criticize an individual without valid evidence.

Information that is considered important and new depends on how quickly a blogger responds to an issue awaited by readers. For example, when big and juicy news occurs, information can be obtained through the mainstream media and readers will also be waiting for materials from blogs that are seen to have the present value of the news. Certain readers would also like to know the news from a different perspective.

Blogger 1 explained that;

"I'm free from any sorts of influence and restrictions and apart from the influence and control of the law, I am free. So of course I can write, stating things that I can't do if I wrote in the newspaper owned by others. Of course I will write something if I think it is not important or relevant to the reader. Sometimes when writing and if one are a fairly well-known writer, what is considered as an unimportant piece of junk would be taken seriously, meaningful and not just another piece of worthless information. "

In other words, something that is considered worthless but when written by a blogger who is influential and has its own identity will make the writing significant and matters. The phenomenon of social media that are easily shared to the public and also a medium has an increasing significant influence to readers and may lead to the occurrence of democratisation.

A blogger will get the attraction of his readers when his writing presented to the community is based on a compilation of views by certain well-known and respected figures, experts in a particular field and results obtained through interview sessions pertinent to critical issues that are still in debate. According to Blogger 6; "I'm just bringing together good views in blogging and not my views alone. I will only give the impression of who I am that suits the idealism that I want to uphold. "Then, the information to reveal to the community is new and significant as it was not published by the mainstream media in the country.

Blogger 3 further stated that if unknown information were given to people in chronological order and writing ideas from others' opinions, it shall make the person obligated to continue to read the post. He said "Sometimes I have thoughts and ideas that might capture the hearts of readers for example I may say perhaps Najib will experience a tsunami from the Malay voters in the next election. Is it interesting? This came to my mind, but it may not come in the mind of others except based on experience. "This will make people to have an open mind to think and also have the potential to influence the opinion of the readers. However issues pertinent to sentiment should stopped for the benefit of all parties.

As cited by Blogger 3, Chetdet.com blog has posted issues that were written with easy description to ensure simpler understanding of the issues discussed and many examples provided were interesting too. This result in the addition of followers as well his identity and credibility were looked highly upon on. 
In addition, most of the issues that are not published by the mainstream media are issues at the advantage of the opposition and does not give benefit the Government. This situation urges specific bloggers to write by giving a fair overview to the readers or people to address the issue. The same issue has been written in different perspectives and it has then become interesting especially for those who have read through the mainstream media whereby they tend to make comparison with what is read through the blog before making an impression out of it.

The information is also considered to be new and important when it is shared to everyone through a third-party blog. This is explained by Bloggers 7; "I have been speculating that Mahathir will create a political relationship with Anwar, and the issue I have raised was paid attention to by the head of Cheras UMNO Division." This has proven that a piece of writing can be considered interesting and influential besides being trusted by others to an extent that it has urged readers to also comment on the issue. It turns out what has been quoted by this blogger were true today where we could see that both leaders had remained in a coalition party known as Pakatan Harapan in hope to lead Malaysia.

Information published by blogger 5 is more accurate when compared to the newspapers. According to Blogger 5, what is sent to the newspapers has been edited and not necessarily it will be published in the newspaper but it is different in a blog where if the information for any events or news is accurately written, everything will be published without any edits made. With this, information is more accurate if it is based on the truth in blogs compared to newspaper. This is proven as there were more than $80 \%$ visitors or his blog readers that agree to what he has written and they are always expecting new disclosure or exposure of issues debated by the mainstream media.

This is also supported by Blogger 2 that his writings often provide important information to readers because it is something new, from his own resources or resources from his colleagues. . Blogger 2 explained that;

"Sometimes journalists have constraints in publishing news because of limitations. They will try to get service from a blogger friend. I will use all the information in a story without the fear of being sued for example or held accountable for by some politicians. In some ways, I can provide issues discussed in the context of history, I can make a Minister to say something, I can also tell my readers pertinent to what is being said by the Minister. So such information and background had helped me to provide something useful for readers."

In other words, the blog has provided new information deemed essential to the readers because it has more freedom to report besides being faster in terms of disseminating information. The easy facilities of blogs also encouraged the community to wait for the next episode of events to be broadcasted by a particular blogger. The easy and fast sharing system as well as the vast space provided has made blogs a popular choice today. In addition, the facilities that allow visitors to rebrowse at any time elevates the use of the blog as a new medium that provides significant, relevant information, and affects the lives of those who read, their position and whatever views they have provided by bloggers is seen as another alternative source for comparison.

\section{The relationship between identity and credibility.}

This section will explore if there is any relationship between the identities of the blogger with the credibility of a person. How strong is the trust and belief of a blogger who remains anonymous in 
his blog can be? This is because there are still many bloggers in Malaysia who do not put their names and only use pen names or nicknames. They are bold in expressing opinions and speak whatever that comes in mind. However, they are not able to escape legal actions too if there is any writing that touches the sensitivities of the multi-racial society and violates the existing rules and constitution.

Although all the interviewed informants have revealed their identity, the question remains as to what extent of the identity disclosure that can affect the credibility of a blog. Meyer (2004) described in the Model of Traditional Media Influence, it is necessary to establish trust in someone in their writing. Credibility can be seen in terms of the identity of a particular blogger. If a blog is wellknown, it is important to know the background of the blogger so that more people will read it. To evaluate the credibility of a blog content, stated by Ohanian (1990), the content written should be credible, the information must also be authentic, accurate and reasonable, as well as displaying compelling writings.

Blogger 5 speaks of the Prime Minister's blog, chedet.com and blogger Kadir Jasin. Whatever discussion posted, there will be a bizarre in the acceptance of the information presented and these blogs are always followed and people awaits for more issues to be discussed and posted by them. "For example, the Prime Minister's blog is quite famous because people know him; he will always bombard issues to be discussed and a food for thoughts. People know his views are logic and relevant. As for blogger A. Kadir Jasin, his blogs has many followers too. Readers are always waiting for what could be next from him. In short, personality and characteristics of a blogger are important to maintain the credibility of a blog.

Blog is also seen as credible if people are paying attention to it and there are effects of what has been posted. Once again, Blogger 5 has named Kadir Jasin, Tun Mahathir, Rocky Bru and Syed "Outside the Box" due to the fact that they had high credibility in their blogs. The style of writing and structure of sentences can also illustrate the identity of a blogger. Sometimes, a blogger is considered exceptional when his writing is different from others, in other words has crossed the line sometimes. Blogger 5 stated that "Once, I too had crossed the line and not realizing what I have done or said, so, evidently we too needed to be governed by the law that reminds us not to cross the line". The limitation that has been governed by the existing law has caused him to be sued by Air Asia for five million ringgit because of a statement condemning Air Asia selling pork during his flight.

There is also a blogger who has revealed his background at the beginning of the blog post and explained the blog's origin, his stand and what his expectations were from readers as most blogger would, and he is Blogger 8 . When reading a blog that does not know who the blog owner is, may result in difficulty in believing what has been written by him. This has been further reinforced by Blogger 1 stating;

"Most people who hid behind the pseudonym or nickname and not knowing the real identity of the blogger may result in difficulty to measure the credibility of the blogger or the blog for the readers."

The not revealing of the identity of a blogger may cause various accusations and an easier platform for defamation to happen. This type of blog tends to be seen as having a higher risk to practice freedom in raising sensitive issues without being held responsible for. So, it is clearly seen that a blogger's identity portrays the credibility of a blog. To know the real identity of a blogger also refers to a blogger with high integrity and being responsible on what has been written and posted in his blogs. 
A blogger's experience in the field of writing contributes to the identity of a blogger too because readers recognised the value of the disseminated information. In addition, bloggers must also maintain their integrity in disseminating information to readers. To which extent the integrity of a blogger in reporting an issue is assessed by thousands of readers and followers. As stated by Blogger, Blogger 7 "The integrity is in the background of a blogger's identity." In other words, identity and integrity are important in a blogger and they are closely linked to each other. It is also acknowledged by Amini Amir (2010) that expressing the integrity of credibility as the principles and standards of this practice will not only produce ethical articles to be published, but it will also lead to the trust of readers on these writings.

In addition, identity lending from a person who has been identified or from an individual who has credibility helps to increase the credibility of a medium. For example as stated by Blogger 2 regarding the 1 MDB issue with Najib Razak that was published by Sarawak Report. At first it did not get much attention and confidence from the readers but when famous blogger Tun Mahathir quoted a story written by Sarawak Report, and he was interviewed again by Sarawak Report, this has then made Sarawak Report a more credible medium. In other words, the identity of Tun Mahathir has clearly helped to raise the credibility of Sarawak Report although this news portal did not state the exact name of the author who wrote the article.

"When he started citing stories and started quoting Sarawak Report and was interviewed by Sarawak Report, the Sarawak Report has become more reliable news portal. Mahathir is an individual who lends his credibility to Sarawak Report. And, this is an example of a true identity of a great blogger like Tun Mahathir definitely has helped."

\section{Freedom of Expression: Empowering Culture of Democracy}

The practice of freedom in the dissemination of information that has taken place today is considered a trigger factor for freedom of expression in cyberspace. The sophistication of technology in line with the era of modernisation has also led to the easy access and the speed in accessing information through the use of information technology. This new technology has opened up vast opportunities for the community to participate in the process of sharing information that could lead to the democratisation era. The emergence of blogs has provided a platform to the public to voice their opinions without limitation through the virtual world.

Blogs rely basically on the internet. The Internet is a platform to freedom of expressing opinions so it has become a reality. On the basis of expanded space, blogs also provide a great opportunity to express opinions compared to other social media such as facebook, twitter, instagram and so on. This is an event to be proud of, but the blogger himself has to be more responsible for all the possible effects of his writing. Overall, all interviewed bloggers agreed that the blog has opened up a large space to express their opinions. Zain et al., (2015), through research also states that the use of the internet has created cyber democracy where people have the freedom to give ideas and express views and for them to gather virtually to discuss issues too.

According to Blogger 6, "the restrictions imposed were not so much compared to the press." So it is uncertain what cannot be conveyed through the Harakah newspaper that can be posted in the blog in hope to be able to provide further clarification to readers. Blogger 2 also agrees with Blogger 6 through its explanation that; 
"I do not believe in short writing because we cannot communicate in a few words. Blog has opened up a space and this is a good and worthwhile platform but the blogger himself needs to be responsible for what will happen as a result of his writing. I want a blog that has credibility. I want a blog that has a sense of responsibility because it is a platform to share ideas, views, and experience. This is the way I am disseminating all these information. "

In other words, the provided platform should be used as efficiently as possible for the dissemination of useful information to the community. Blog users should have a sense of responsibility while blogging. In addition, the platform given should also be used by channeling right things and good arguments to practice freedom of writing. Blogger 7 explained again that blog has provided a privilege to its users as it is a free medium which allows bloggers to write irreversible stories and can be channeled directly to the readers. It is proven worthwhile and provides freedom especially if it is used to convey something good. "I can write anything and send information in just a few hours to the readers without any need for filtering, to certain processes before ideas are delivered."

This is also supported by Blogger 1 stating that;

"I am not hired by anyone, not paid by anyone and not licensed by anyone. My freedom is only subject to laws such as acts of sedition, official secret acts, defamation acts, and issues only. "

Due to the distressing feeling that many of the written articles that were sent to Mingguan Malaysia, Utusan Malaysia were not featured and published by the press, Blogger 3 had taken the approach to include his article which sometimes can be sensitive to what was happening in the country in the blog. It is also acknowledged by Blogger 5 who always uses blogs to voice his views. Many sensitive issues happening in the country were exposed through blogs. "But we cannot do so through the newspaper because at times reporters may not want to do so. We can then put it in a blog, the views and issues of what we are saying. We can just write in the blog. "Additionally, Blogger 8 states that blogs have empowered individuals by providing a platform to promote issues and agendas.

\section{Freedom in blogging in Malaysia}

Blogs are seen as a free medium by all the bloggers interviewed except for one Blogger who is blogger 8 whom has his own viewpoint by saying that blogs should not practice freedom as bloggers should always be careful about what is written. The reason why his blog was not viewed as negative because it is written in English which requires a high level of understanding and not many people in Malaysia who can read and understand English language that he had used in his blog. Examples of statements used in his blog were, "I'm not saying that he takes bribe, but I am saying that he is incompetent." So the writing style and language used can distract people from negative viewpoints against him.

The different notions about the concept of freedom were given by bloggers; Blogger 6 stated that in this principle of freedom, mostly importantly is the platform provided. Being taken legal actions should not be viewed as negative. It is just a reminder that everything done is definitely a risk and there is an obligation to follow rules and regulations. Such restrictions have never affected his decision to continue giving ideas and to share his expertise with the community. In short, there is 
freedom in blogging but not absolute and what is happening today is a process of maturation in the differences of viewpoints through blogs. Blogger 5 also agreed with Blogger 6 through its description; "Generally bloggers are free to write on anything. But one shall not forget one is bound by the law and acts. He can write anything as long as he does not violate those things, and do not defame people. This blog does not condemn people, or kings, race, and religion. "

However, there are people who deny that freedom in Malaysia is being controlled by a communication commissioner and so on but in Blogger 7's view, "freedom is still given to us, the restrictions are only when these writings have violated some specific facts for example violating the act of sedition, defamatory acts excessively." This is also supported by Blogger 1, Blogger 2, Blogger 3 and Blogger 4 stating that in Malaysia, blogs practice freedom of speech. Freedom of speech takes place significantly in Malaysia where one can open anonymous blogs and create a dispute with others. They can criticise the Prime Minister, the Opposition Leader and do whatever it takes because the authorities will not take actions such as by closing the blog's account. Legal actions are simply just suing the bloggers for sedition, defamation and extortion. Abdullah et al. (2017) through the blog content analysis method to look at the blog by viewing the tone for the news in a review period of two months before and two months after the 13 th General Election showed that $73.7 \%$ of the total sample (836) was at the level of anti-written and pro-written tone and bloggers seemed to express their opinions openly without needing to hide. "

Freedom in writing a real blog takes place in Malaysia today, but when it comes to freedom, it does not mean that bloggers are free to write anything because they still have to maintain the sensitivities of being multiracial, religious practice and other societies too. So bloggers should be more selective in using the freedom that has been given. In other words bloggers can say anything but they are still subject to abide the existing laws.

\section{The Legal effects on blogging}

In general, bloggers are aware of the existence of various acts and laws that can be taken on them if there are negative elements or sensitive issues posted on blogs. Bloggers should always be careful about blogging so all posted articles and comments should touch on the sensitivities in a multiracial Malaysian society. As a blogger, there is no escape on legal actions if found guilty of cybercrime such as defaming, threatening, inciting, falsifying documents, denouncing human rights and so on. Bloggers should not only be cautious about the dissemination of information through its published articles but also all the comments made should be carefully written and they must always be responsible for the ideas or opinions that are posted in blogs too.

Malaysia is a country which has a constitution or acts and laws, so everything done must be subject to the laws that have been enacted. Actions done by anyone must be controlled because wrong steps will cause certain parties to file a suit. The freedom practiced is not for free. The existence of these laws and acts is to warn the bloggers to not to be too voracious in their writing so as to forget the real responsibility of being a writer to convey true information, based on authentic facts that can help the society to make comparisons between media that are available in the country.

Events that could be categorised as incitement for example are arguing over matters in the constitution, the position of the Malay rulers, the position of Malay language and the rights of learning other languages, the privileges of the Malays and Sarawak Sabah children, questioning the 
position of Islam as federal religion and religious rights and other religious beliefs, dispute the citizenship or immigrant rights. All of these issues are considered as seditious.

If a blogger criticises the government, individuals, including political leaders, these are not considered as seditious. Unless he incites others in order to cause disorder, disrupt public order and cause people to do wrong things that violates the law. Blogger who writes with the objective to influence people to not support a politician is not considered as incitement. It is a common feature used in democratic politics.

According to blogger 7;

"The laws in Malaysia do not give any effect to restrict and limit my personal writing. Perhaps it is because I'm too controlling over my writing or I follow the set of ethics in blogs. "

Hence, the existing law does not affect his writing. No sense of threats behind the drafted act is said to be a threat to blog writing. However, he views that the Sedition Act 1948 is a law-abiding act. This is supported by blogger 6 by stating that;

"I am aware of the existence of laws and laws that can be attributed to bloggers but it does not affect my writing in comparison to the newspaper."

Blogger 8 also supports statements made by Blogger 6 and Blogger 7 by explaining that the existing laws have no negative effects on his writing. He added "When you write you do not have to condemn someone directly. You can do it in a different way. So far I have no problem besides the one case that I remembered when Raja Petra said I was part of a team that opposed Najib." To prevent writing being taken legal actions on, writing and criticism should be done prudently.

Blogger 3 has also given clarification by associating himself with the statement that Air Asia has accused him of claiming that Air Asia had supplied pork dishes in their service during his flight with Air Asia through his blog post. This should be a warning to all bloggers that there is no such thing as "a real freedom of speech in Malaysia". In other words, the freedom given is not absolute and bloggers are still subject to various laws and acts that are available within the country. Therefore, bloggers should always be sensitive and careful in disseminating information to readers.

Blogger 2 also acknowledged that he was the first blogger to sue a press company. Even though he has been convicted, he mentioned that this has not affected his writing by saying that "bloggers should not be imposed or restricted from expressing their opinions or following the news or exposing wrongdoing as we see is happening today, highlighting what Tun Mahathir did to expose what he believed was untrue."

Blogger 1 believes that bloggers are part of a community member and they are not immune from punishment and have any special privilege. The privilege lies in the fact that the constitution guarantees freedom of expression and expressing viewpoints. The laws and regulations play an important role in determining whether a blogger is safe or unsafe from being taken legal actions. Blogger is subject to official secret act, sedition act, defamatory act and more. Today, many bloggers and new media users are facing legal actions such as are being detained, investigated and charged for not understanding this undisputed law in Malaysia.

Blogger 1 also explains that;

"The law has no effect on my writing but we have to take our own risk. We have to bear in mind that there is a risk like myself being sued; I personally receive a letter from a lawyer when I wrote about a 
particular person's attributes. For me, that is courage ... if we have the courage, we can try to expand our writing without any boundaries but the risks remain."

Blogger 5 and Blogger 4 also agreed that they were aware of the existence of various acts and laws with the objective of safeguarding public order and national harmony. However, the laws that exist in the country have never affected their writing. Blogger 4 stated "as long as we do not instigate, do not encourage violence, not deceiving, defamatory, ignorant of religion or invoking misguided teachings, we then are free to write." Blogger 5 explains again that Malaysia laws and acts were never condescending unless we act in extreme ways. "Malaysia is a democratic state, a racial, cultural and religious racial country." The parliamentary democracy itself allows freedom of speech. Thus, the law created is not to punish media users but as guidelines for today's social media users so that they will be more attentive and responsible in their writing. The findings of Abdullah et al. (2018) also noted that the Malaysian bloggers who were the subject of a study are aware of the laws that may be applicable to them and have set the accountability at a high level and will always be responsible for any harms that will be presented as a result of their writing while ensuring legitimacy information is obtained.

\section{Conclusion}

In conclusion, the exposure to the blogger's identity has led to the rise of a blog's credibility. People tend to put more trust and belief in information that are widely spread from well-known and established bloggers compare to the information that was disseminated from bloggers who tend to hide their identity. Nevertheless, borrowed identity from a person or an individual who has credibility helps to increase the credibility of the medium too. Thus, bloggers in Malaysia are advised to disclose their identity to the public so that their blogs may attract more ready to drop by readers and are always ready with their writings. The content of information supplied must be authentic, accurate and reasonable as well as displaying a compelling writings.

Blogs in Malaysia have also opened up a useful platform for bloggers to point out ideas after the results of the study showed that bloggers are bold and free to express opinions either by supporting or opposing an issue or policy. The blog has become a reality platform to freedom of expressing opinions. The restrictions imposed to blogs were not so much compared to the press. Study has shown that the power of blogs' postings have greatly influenced the public and empowering the culture of democracy in Malaysia. Blogs have opened a space to express what they feel but the blogger himself needs to be responsible for the implications that come together with the writings. Bloggers should put accountability at a higher level because accountability will lead to the credibility of the blogs' postings. Accountability will also lead towards higher integrity amongst bloggers.

However, it should be noted that freedom given is not an absolute freedom because bloggers must still abide the laws in Malaysia. Today's blog is closely related to politics. Blog has indirectly led to a strong influence in the political world in Malaysia. The laws and regulations play an important role in determining whether a blogger is safe or unsafe from being taken legal actions. Hence, bloggers should always be aware and cautious in disseminating information to the public. This is due to the fact that by writing to expose untrue or false information may lead to the risk of being sued under certain acts like Sedition Act 2015, Defamation Act 1957, False News Act 2018, and etc. In 
preventing the writing from being taken legal actions, bloggers should write and criticise prudently besides practicing being sensitive in disseminating information to the public or readers. The existence of these laws and acts is to warn the bloggers to not to be too voracious in their writing so as to forget the real responsibility of being a writer to convey true information, based on authentic facts that can help the society to make comparisons between media that are available in the country.

\section{Acknowledgement}

We thank Dr Abdul Latiff Ahmad from Universiti Kebangsaan Malaysia for his assistance with qualitative methodology and comments that greatly improved the manuscript.

\section{Corresponding Author}

Muhammad Hakimi Tew Abdullah (PhD)

Faculty of Communication and Media Studies

Universiti Teknologi MARA (UiTM),

Negeri Sembilan Branch Campus,

Malaysia.

\section{References}

Abdullah, M. H. T., Khamis, M. H. \& Azni, Z. M. (2018). Pendemokrasian maklumat blog: Isu akauntabiliti dalam kalangan blogger di Malaysia. Jurnal Komunikasi, Malaysian Journal of Communication. Vol. 34(3), 361-378.

Abdullah, M. H. T., Ahmad, A. L. \& Jing, H. F. (2017). The disclosure of media framing between bloggers in Malaysia. Journal of Media and Information Warfare. Vol. 9, 1-22.

Abdullah, M. H. T., Ahmad, A. L. \& Kee, C. P. (2016). The exposure of media frames among Malaysian bloggers pre and post 13th general election. Jurnal Komunikasi, Malaysian Journal of Communication. Vol. 32(2): 425-452.

Akmal, F. \& Salman, A. (2015). Partisipasi politik belia secara 'online'melalui ruang demokrasi maklumat media baru. Jurnal Komunikasi, Malaysian Journal of Communication. Vol 31(1): 81100.

Amini Amir (2010). Nilai integriti dan akauntabiliti. Retrieved from http://aminiamir.blogspot.com/2010/01/nilai-integriti-dan-akauntabiliti.html

Baharuddin Aziz, Abdul Rasid Abdul Rahman \& Rahmat Ghazali. (2008). Kajian Mengenai Peranan dan Pengaruh Internet dan Kewartawanan Bloggers Terhadap Para Pengundi Semasa Pilihan Raya Umum Malaysia 2008. Universiti Teknologi MARA, RMI.

Inch, A. (2015). Ordinary citizens and the political cultures of planning: In search of the subject of a new democratic ethos. Planning Theory 14(4): 404-424.

Koop, R. (2006). Canadian political blog: online soapboxes or forums for democratic dialogue? Retrieved from http://www.cpsa-acsp.ca/papers-2006/Koop-Jansen.pdf.

Roth, M. M. (2004). How journalist see the blogshere. Retrieved from http://www.asc.upenn.edu/usr/mmccoy/blogs.pdf 
Meyer, P. (2004). The varnishing newspaper: Saving journalism in the information age. Columbia University of Missouri Press.

Ohanian, R. (1990). Construction and validation of a scale to measure celebrity endorsers' perceived expertise, trustworthiness and attractiveness. Journal of Advertising, 19 (3), 39-52.

Tang, H. W. (2006). Let a Hundred Flowers Bloom: Digital Speech in Malaysia. Asian Journal of Comparative Law, 1(1). Retrieved from http://www.bepress.com/asjcl/vol1/iss1/art12

Zain, Z. M, Yusoff, M. A. \& Othman, Z. (2015). Internet dan kebangkitan demokrasi siber di Malaysia: Analisis Pilihan Raya Umum 1999 dan 2008. Malaysian Journal of Society and Space 11(5): 5666. 